\title{
Ceftolozane/tazobactam and ceftazidime/avibactam antimicrobial activity against clinically relevant gram-negative bacilli isolated in Mexico
}

\author{
Rafael Martínez-Miranda, ${ }^{1 *}$ Mariana Gastélum-Acosta, ${ }^{1}$ Paloma Guerrero-Estrada, ${ }^{1}$ \\ Rafael I. Ayala-Figueroa ${ }^{2}$ and Luis E. Osuna-Álvarez ${ }^{3}$ \\ ${ }^{1}$ Department of Clinical Microbiology, Faculty of Medicine, Universidad Autónoma de Baja California; ${ }^{2}$ Department of Statistics, Faculty of Medicine, \\ Universidad Autónoma de Baja California; ${ }^{3}$ Department of Pediatrics, Hospital General de Mexicali. Baja California, Mexico
}

\begin{abstract}
Introduction: There is limited information on the effectiveness of ceftolozane/tazobactam and ceftazidime/avibactam combinations on clinically relevant strains isolated in Mexico. Objective: To determine the antimicrobial profile of both antibiotic combinations in our community. Method: The present research study was prospective, descriptive and cross-sectional. Clinically relevant strains isolated from pure-strain cultures were included during the period from August 2018 to January 2019 in Mexicali, Baja California, Mexico. Results: 74 enterobacteriaceae and 19 Pseudomonas aeruginosa strains were analyzed; the percentage of sensitivity of ceftazidime/avibactam was $100 \%$ for enterobacteriaceae and $72.7 \%$ for Pseudomonas aeruginosa; the percentage of sensitivity of ceftolozane/tazobactam for enterobacteriaceae was $90.5 \%$ and $72.7 \%$ for Pseudomonas aeruginosa. Conclusions: The ceftolozane/tazobactam and ceftazidime/avibactam combinations offer good antimicrobial sensitivity in vitro, both for ESBL-producing enterobacteriaceae and Pseudomonas aeruginosa. More data are required to assess clinical response in patients receiving these antibiotic combinations.
\end{abstract}

KEY WORDS: Cephalosporins. Beta-lactamase inhibitors. Multi-drug resistance.

\section{Actividad antimicrobiana de ceftolozano-tazobactam y ceftazidima-avibactam contra bacilos gramnegativos clínicamente relevantes aislados en México}

\section{Resumen}

Introducción: Existe poca información acerca de la efectividad de las combinaciones ceftolozano/tazobactam y ceftazidima/avibactam en cepas clínicamente relevantes aisladas en México. Objetivo: Determinar el perfil antimicrobiano de ambos antibióticos en nuestra comunidad. Método: El presente estudio de investigación fue prospectivo, descriptivo y transversal. Se incluyeron cepas clínicamente relevantes aisladas a partir de cultivos de cepa pura durante el periodo de agosto de 2018 a enero de 2019 en Mexicali, Baja California, México. Resultados: Se analizaron 74 cepas de enterobacterias y 19 cepas de Pseudomonas aeruginosa; el porcentaje de sensibilidad de ceftazidima/avibactam fue de $100 \%$ contra enterobacterias y de $72.7 \%$ contra Pseudomonas aeruginosa; el porcentaje de sensibilidad de ceftolozano/tazobactam fue de $90.5 \%$ para enterobacterias y de $72.7 \%$ para Pseudomonas aeruginosa. Conclusiones: Las combinaciones ceftolozano/tazobactam y ceftazidima/avibactam ofrecen buena sensibilidad antimicrobiana in vitro, tanto contra enterobacterias productoras de betalactamasas de espectro extendido como contra Pseudomonas aeruginosa. Se requieren más datos para valorar la respuesta clínica en pacientes que reciben esas combinaciones de antibióticos.

PALABRAS CLAVE: Cefalosporinas. Inhibidores de betalactamasas. Resistencia a múltiples fármacos.

Correspondence:

*Rafael Martínez-Miranda

E-mail: rmartinez90@uabc.edu.mx
Gac Med Mex. 2020;156:592-597

Contents available at PubMed

www.gacetamedicademexico.com

0016-3813/@ 2020 Academia Nacional de Medicina de México, A.C.. Published by Permanyer. This is an open access article under the CC BY-NC-ND license (http://creativecommons.org/licenses/by-nc-nd/4.0/). 


\section{Introduction}

Gram-negative bacteria antimicrobial resistance has become one of the main causes of morbidity and mortality and a serious public health problem in the world. ${ }^{1}$ The increasing prevalence of extended-spectrum beta-lactamase (ESBL)- and carbapenemase-producing strains in recent years constitutes a challenge due to resistance mechanisms easy dispersal, difficulty for choosing an appropriate antimicrobial treatment, and increased hospital stay time.,2,3

Ceftolozane/tazobactam (C/T) and ceftazidime/avibactam (CZ/A) are two new cephalosporin combinations with antimicrobial spectrum against $P$ seudomonas aeruginosa, as well as against ESBL- and carbapenemase-producing enterobacteriaceae of clinical interest. In 2014, both antibiotic combinations received approval from the United States Food and Drug Administration and, in 2017, in Mexico, by the Federal Commission for the Protection against Sanitary Risks, for the treatment of complicated urinary and intra-abdominal infections. ${ }^{4-6}$

There is little information regarding the effectiveness of these antibacterial drugs against strains isolated in Mexico; ${ }^{7,8}$ therefore, the purpose of this research project was to determine the susceptibility profile of both antibiotic combinations in our community.

\section{Method}

This research study was prospective, descriptive and cross-sectional. Ninety-three clinically relevant strains isolated from pure strain cultures were included between August 2018 and January 2019, with the participation of the MD Microbiología Clínica, S. de R.L. de C.V. laboratory (Mexicali, Baja California, Mexico) and the Clinical Microbiology laboratory of the Faculty of Medicine of the Autonomous University of Baja California, Mexicali campus. The origin of the samples for microbiological analysis was multiple, including urine, bronchial secretion, blood, secretions from wounds and abscesses, synovial fluid, soft tissue and bone biopsies, peritoneal fluid and cerebrospinal fluid.

Processing of the biological samples was carried out according to the American Society for Microbiology clinical microbiology procedures manual. ${ }^{9}$ In all types of samples, $5 \%$ ram blood agar and Maconkey agar were inoculated; methylene blue eosin agar and trypticasein soy agar were added to the urine cultures; cerebrospinal fluid and blood cultures had chocolate agar added. Tissue biopsy samples were macerated in a mortar and a ram brain-heart infusion broth was inoculated to subsequently add blood agar, Maconkey agar and chocolate agar. The cultures were incubated at $37{ }^{\circ} \mathrm{C}$ for 24 to 72 hours under aerobic conditions and with $5.5 \%$ carbon dioxide (Shellab ${ }^{\circledR}$ incubator, model SCO6AD, SheloLab); no incubation was carried out under anaerobic conditions.

Once the strains were developed, they were identified using Biomérieux Vitek $2^{\circledR}$ Compact automated system, which uses identification cards for Gram-negative bacilli and Gram-positive cocci; the Gram-negative identification card consists of 47 biochemical tests and one negative control well. The procedure for filling out the card is the following:

- $3 \mathrm{~mL}$ of sterile saline $(0.45-0.50 \% \mathrm{NaCl}$ with $\mathrm{pH}$ 4.5 to 7.0 ) are aseptically transferred to a $12 \mathrm{x}$ $75 \mathrm{~mm}$ polystyrene tube.

- With a sterile microbiological inoculating loop, a sufficient number of colonies are collected to prepare a homogeneous suspension equivalent to 0.5 McFarland units.

- The tube with the suspension and the card are placed in a rack that is specially designed to be introduced in the automated equipment.

To measure $\mathrm{CZ} / \mathrm{A}$ and $\mathrm{C} / \mathrm{T}$ antimicrobial activity, the disk diffusion technique was used in Mueller-Hinton agar, as stipulated by the procedures in document M100-S28 ${ }^{10}$ of the United States Institute of Clinical and Laboratory Standards; for the antibiogram of the rest of the antibiotics, Vitek $2^{\circledR}$ Compact system cards were used for Gram-negative bacilli AST-XN05 (ampicillin/sulbactam, aztreonam, cefepime, cefexime, ceftriaxone, cefuroxime, chloramphenicol, colistine, ESBL detection, levofloxacin, meropenem, minocycline, moxifloxacin, piperacillin, tetracycline, ticarcillin/ clavulanic acid, tigecycline, trimethoprim) and AST-N285 tests (amikacin, amoxicillin/clavulanic acid, ampicillin, cefazolin, cefoxitin, ceftazidime, ceftriaxone, ciprofloxacin, doripenem, ertapenem, ESBL detection, gentamicin, imipenem, meropenem, nitrofurantoin, piperacillin/tazobactam, trimethoprim/sulfamethoxazole). The automated antibiogram procedure is as follows: from a bacterial suspension with a turbidity of 0.5 McFarland units, $14 \mu \mathrm{L}$ are transferred to a polystyrene tube with $3 \mathrm{~mL}$ of saline; subsequently, the corresponding antibiogram card is inserted in the rack with the tube and introduced into the equipment. 
Table 1. Enterobacteriaceae and Pseudomonas aeruginosa sensitivity to $\mathrm{CZ} / \mathrm{A}$ and $\mathrm{C} / \mathrm{T}$

\begin{tabular}{|c|c|c|c|c|}
\hline \multirow[t]{2}{*}{ Microorganism } & \multirow[t]{2}{*}{ Type of sample } & \multirow[t]{2}{*}{ No. of samples } & \multicolumn{2}{|c|}{ Sensitivity (\%) } \\
\hline & & & CZ/A & $\mathrm{C} / \mathrm{T}$ \\
\hline \multicolumn{5}{|l|}{ Enterobacteriaceae } \\
\hline \multirow[t]{2}{*}{ Escherichia coli } & Urine & 58 & 100 & 88 \\
\hline & Others & 4 & 100 & 100 \\
\hline \multirow[t]{2}{*}{ Klebsiella spp. } & Urine & 4 & 100 & 100 \\
\hline & Others & 1 & 100 & 100 \\
\hline \multirow[t]{2}{*}{ Salmonella } & Urine & 0 & NT & NT \\
\hline & Others & 2 & 100 & 100 \\
\hline \multirow[t]{2}{*}{ Enterobacter aerogenes } & Urine & 0 & NT & NT \\
\hline & Others & 1 & 100 & 100 \\
\hline \multirow[t]{2}{*}{ Morganella morganii } & Urine & 0 & NT & NT \\
\hline & Others & 1 & 100 & 100 \\
\hline \multirow[t]{2}{*}{ Proteus mirabilis } & Urine & 1 & 100 & 100 \\
\hline & Others & 1 & 100 & 100 \\
\hline \multirow[t]{2}{*}{ Serratia marcescens } & Urine & 0 & NT & NT \\
\hline & Others & 1 & 100 & 100 \\
\hline \multirow[t]{2}{*}{ Pseudomonas } & Bronchial secretion & 11 & 72.72 & 72.72 \\
\hline & Others & 8 & 75 & 75 \\
\hline
\end{tabular}

$\mathrm{NT}=$ not tested, $\mathrm{CZ} / \mathrm{A}=$ ceftazidime/avibactam, $\mathrm{C} / \mathrm{T}=$ ceftolozane/tazobactam

Interpretation of the automated microdilution and disk diffusion results was based on document M100-S28 cutoff points.

For statistical analysis, susceptibility and resistance percentages were calculated. McNemar test was used to compare antibiotics' effectiveness, with a p-value $<0.05$ being regarded as significant.

\section{Results}

Seventy-four enterobacteriaceae and 19 Pseudomonas aeruginosa strains were analyzed. CZ/A sensitivity percentage was $100 \%$ for enterobacteriaceae and $72.7 \%$ for Pseudomonas aeruginosa (Table 1); as for $\mathrm{C} / \mathrm{T}$, sensitivity percentage was $90.5 \%$ for enterobacteriaceae and $72.7 \%$ for $P$. aeruginosa. The most common sample of infectious origin was urine, with $68.8 \%$ of total samples (Table 1). Twenty-five ESBL-producing and one carbapenemase-producing enterobacteriaceae were found. Tables 2 and 3 show the sensitivity percentages of the strains for the rest of the tested antibiotics.

\section{Discussion}

$\mathrm{CZ} / \mathrm{A}$ and $\mathrm{C} / \mathrm{T}$ are new antibiotic combinations that have been introduced to the market with promising results against multidrug resistant bacteria. ${ }^{11}$ Current problem of bacterial resistance ${ }^{12}$ has turned into an important public health issue. The results show that these new combinations of cephalosporin with beta-lactamase inhibitors are good options when making a therapeutic decision in our setting, and for this reason we decided to submit the information so far obtained as a brief communication.

CZ/A showed a higher sensitivity for ESBL-producing enterobacteriaceae in comparison with $\mathrm{C} / \mathrm{T}$ (100\% vs. $80 \%)$. Both drug combinations showed superior antimicrobial activity in comparison with commonly-used antibiotics in enterobacteriaceae, such as quinolones (100\% vs. $56 \%$ ), cephalosporins (100\% vs. $63.4 \%$ ), and penicillins (100\% vs. $24 \%$ ). In Pseudomonas isolates, $\mathrm{CZ} / \mathrm{A}$ and $\mathrm{C} / \mathrm{T}$ showed higher activity $(73.6 \%$ sensitivity) in comparison with carbapenem antibiotics 
Table 2. Enterobacteriaceae sensitivity to clinically used antibiotics

\begin{tabular}{|c|c|c|c|c|c|c|c|c|}
\hline Antibiotic & Sensitivity & $\begin{array}{c}\text { Escherichia } \\
\text { coli (62) }\end{array}$ & $\begin{array}{c}\text { Klebsiella } \\
\text { spp. (5) }\end{array}$ & $\begin{array}{c}\text { Salmonella } \\
\text { (2) }\end{array}$ & $\begin{array}{l}\text { Enterobacter } \\
\text { aerogenes (1) }\end{array}$ & $\begin{array}{c}\text { Morganella } \\
\text { morganii }\end{array}$ & $\begin{array}{l}\text { Proteus } \\
\text { mirabilis }\end{array}$ & $\begin{array}{c}\text { Serratia } \\
\text { marcescens }\end{array}$ \\
\hline \multirow[t]{2}{*}{ AMP } & No. of strains & 49 & 4 & NT & NT & NT & 2 & NT \\
\hline & Sensitivity & $24 \%$ & $0 \%$ & NT & NT & NT & $50 \%$ & NT \\
\hline \multirow[t]{2}{*}{ AMC } & No. of samples & 27 & 4 & NT & NT & NT & NT & NT \\
\hline & Sensitivity & $44 \%$ & $50 \%$ & NT & NT & NT & NT & NT \\
\hline \multirow[t]{2}{*}{ SAM } & No. of samples & 34 & 1 & 2 & 1 & 1 & 2 & NT \\
\hline & Sensitivity & $38.23 \%$ & $0 \%$ & $100 \%$ & $100 \%$ & $100 \%$ & $50 \%$ & NT \\
\hline \multirow[t]{2}{*}{ CXM } & No. of samples & 34 & 2 & 2 & 1 & NT & 2 & NT \\
\hline & Sensitivity & $57.14 \%$ & $0 \%$ & $0 \%$ & $0 \%$ & NT & $50 \%$ & NT \\
\hline \multirow[t]{2}{*}{ CXM axetil } & No. of samples & 32 & 1 & 2 & 1 & NT & 2 & NT \\
\hline & Sensitivity & $56 \%$ & $0 \%$ & $0 \%$ & $0 \%$ & NT & $50 \%$ & NT \\
\hline \multirow[t]{2}{*}{ CRO } & No. of samples & 62 & 5 & 2 & 1 & 1 & 1 & NT \\
\hline & Sensitivity & $64.51 \%$ & $40 \%$ & $100 \%$ & $100 \%$ & $100 \%$ & $100 \%$ & NT \\
\hline \multirow[t]{2}{*}{ FEP } & No. of samples & 35 & 3 & 2 & 1 & 1 & 2 & NT \\
\hline & Sensitivity & $68.57 \%$ & $33 \%$ & $100 \%$ & $100 \%$ & $100 \%$ & $50 \%$ & NT \\
\hline \multirow[t]{2}{*}{ ETP } & No. of samples & 51 & 5 & NT & NT & 1 & 2 & NT \\
\hline & Sensitivity & $98 \%$ & $100 \%$ & NT & NT & $100 \%$ & $100 \%$ & NT \\
\hline \multirow[t]{2}{*}{ MEM } & No. of samples & 62 & 5 & 2 & 1 & 1 & 2 & NT \\
\hline & Sensitivity & $96.77 \%$ & $100 \%$ & $100 \%$ & $100 \%$ & $100 \%$ & $100 \%$ & NT \\
\hline \multirow[t]{2}{*}{ LVX } & No. of samples & 62 & 5 & 2 & 1 & 1 & 2 & NT \\
\hline & Sensitivity & $56.45 \%$ & $80 \%$ & $100 \%$ & $100 \%$ & $0 \%$ & $50 \%$ & NT \\
\hline \multirow[t]{2}{*}{ CIP } & No. of samples & 58 & 4 & 2 & 1 & 1 & 2 & NT \\
\hline & Sensitivity & $56.89 \%$ & $100 \%$ & $100 \%$ & $100 \%$ & $0 \%$ & $50 \%$ & NT \\
\hline \multirow[t]{2}{*}{ AMK } & No. of samples & 55 & 3 & NT & NA & 1 & 2 & NT \\
\hline & Sensitivity & $98.18 \%$ & $100 \%$ & NT & NA & $100 \%$ & $100 \%$ & NT \\
\hline \multirow[t]{2}{*}{ GEN } & No. of samples & 49 & 4 & NT & NA & 1 & 2 & NT \\
\hline & Sensitivity & $72.00 \%$ & $75 \%$ & NT & NA & $0 \%$ & $50 \%$ & NT \\
\hline \multirow[t]{2}{*}{ SXT } & No. of samples & 51 & 4 & 2 & 1 & 1 & 2 & NT \\
\hline & Sensitivity & $65 \%$ & $25 \%$ & $100 \%$ & $100 \%$ & $0 \%$ & $100 \%$ & NT \\
\hline \multirow[t]{2}{*}{ NIT } & No. of samples & 53 & 4 & NT & NT & NA & 2 & NT \\
\hline & Sensitivity & $84.90 \%$ & $25 \%$ & NT & NT & NA & $50 \%$ & NT \\
\hline \multirow[t]{2}{*}{ FOS } & No. of samples & 54 & 4 & NT & NT & NA & 2 & NT \\
\hline & Sensitivity & $94.44 \%$ & $25 \%$ & NT & NT & NA & $100 \%$ & NT \\
\hline
\end{tabular}

$\mathrm{NT}=$ not tested, $\mathrm{AMP}=$ ampicillin, $\mathrm{AMC}=$ amoxicillin/clavulanic acid, $\mathrm{SAM}=$ ampicillin/sulbactam, $\mathrm{CXM}=$ cefuroxime, $\mathrm{CRO}=$ ceftriaxone, $\mathrm{FEP}=$ cefepime, $\mathrm{ETP}=$ ertapenem, $\mathrm{MEM}=$ meropenem, $\mathrm{LVX}=$ levofloxacin, $\mathrm{CIP}=$ ciprofloxacin, $\mathrm{AMK}=$ amikacin, $\mathrm{GEN}=$ gentamicin, $\mathrm{SXT}=$ trimethoprim/sulfamethoxazole, NIT = nitrofurantoin, FOS = fosfomycin. 


\begin{tabular}{|c|c|c|}
\hline Antibiotics & Sensitivity & Pseudomonas $(n=19)$ \\
\hline \multirow[t]{2}{*}{ Ticarcillin/AC } & No. of strains & 16 \\
\hline & Sensitivity & 12.5 \\
\hline \multirow[t]{2}{*}{ Piperacillin/T } & No. of samples & 19 \\
\hline & Sensitivity & 52.63 \\
\hline \multirow[t]{2}{*}{ Ceftazidime } & No. of samples & 17 \\
\hline & Sensitivity & 64.7 \\
\hline \multirow[t]{2}{*}{ Cefepime } & No. of samples & 18 \\
\hline & Sensitivity & 61.11 \\
\hline \multirow[t]{2}{*}{ Imipenem } & No. of samples & 18 \\
\hline & Sensitivity & 38.88 \\
\hline \multirow[t]{2}{*}{ Meropenem } & No. of samples & 19 \\
\hline & Sensitivity & 42.1 \\
\hline \multirow[t]{2}{*}{ Levofloxacin } & No. of samples & 19 \\
\hline & Sensitivity & 36.84 \\
\hline \multirow[t]{2}{*}{ Ciprofloxacin } & No. of samples & 19 \\
\hline & Sensitivity & 31.57 \\
\hline \multirow[t]{2}{*}{ Amikacin } & No. of samples & 17 \\
\hline & Sensitivity & 58.82 \\
\hline \multirow[t]{2}{*}{ Colistin } & No. of samples & 18 \\
\hline & Sensitivity & 94.44 \\
\hline
\end{tabular}

(meropenem $42.1 \%$, imipenem $38.8 \%$ ) and anti-pseudomonas such as amikacin (58.82\%), piperacillin/tazobactam (52.3\%), ceftazidime $(64.7 \%)$ and cefepime $(61.1 \%)$, which places them as the most sensitive antibiotics, only after colistin (94.4\%).

In addition to the comparison that was made with the new drugs of interest, this study shows at the same time the elevated resistance of strains to several antibiotics considered first-choice for Gram-negative bacteria such as cefuroxime, ceftriaxone, levofloxacin and ciprofloxacin, with approximately $40 \%$ resistance of Escherichia coli and $50 \%$ of Pseudomonas aeruginosa to carbapenems, $40 \%$ to anti-pseudomonas penicillins and around $30 \%$ resistance to aminoglycosides. These resistance patterns observed in our community are similar to those reported in recent publications $^{12}$ and should be considered by the clinician at the time of making a therapeutic decision.

In conclusion, the $\mathrm{CZ} / \mathrm{A}$ and $\mathrm{C} / \mathrm{T}$ combinations have a good response in vitro, especially with regard to ESBL-producing enterobacteriaceae and Pseudomonas aeruginosa. CZ/A and $\mathrm{C} / \mathrm{T}$, when compared with antibiotics that are conventionally used in clinical practice for infections caused by enterobacteriaceae, did not show a statistically significant difference with regard to meropenem ( $p=1$ vs. $p=0.625$, respectively), but were clearly superior to ceftriaxone ( $p<0.01$ vs. $p<0.01$ ). As for Pseudomonas aeruginosa, due to the reduced number of strains, it is not pertinent to claim statistical superiority of $\mathrm{CZ} / \mathrm{A}$ and $\mathrm{C} / \mathrm{T}$ in comparison with other anti-pseudomonas antibiotics such as colistin and meropenem.

Although CZ/A and C/T can be quite useful in the management of highly resistant Gram-negative microorganisms, currently available data to support their clinical efficacy in Mexico are still limited. Another aspect to consider is the economic cost, which can be almost double when compared to other antibiotics that showed similar antimicrobial activity, such as carbapenems and aminoglycosides.

We strongly advise judicious use of the susceptibility data obtained with this research, since the frequency of pathogenic strains isolation, as well as bacterial resistance can considerably vary between different geographical regions, even between hospitals in the same city. It is essential to know the specific epidemiological situation of the place we are located in, the most commonly isolated bacteria in the community, as well as their resistance patterns, which will allow guiding antibiotic treatment with less margin of error. ${ }^{13}$

One limitation of the present investigation was that the reagents to perform $\mathrm{CZ} / \mathrm{A}$ and $\mathrm{C} / \mathrm{T}$ microdilution were not available, which is why comparing in vitro strength between both antibiotics against the identified strains was not possible.

\section{Acknowledgements}

We are grateful for the valuable support provided by pharmaceutical chemist biologist Martha Dorado del Río in the processing of clinical-origin samples.

\section{Conflicts of interest}

The authors declare that they have no conflicts of interest. 


\section{Funding}

The authors received no sponsoring to carry out this article.

\section{Ethical disclosures}

Protection of human and animal subjects. The authors declare that no experiments were performed on humans or animals for this investigation.

Confidentiality of data. The authors declare that no patient data appear in this article.

Right to privacy and informed consent. The authors declare that no patient data appear in this article.

\section{References}

1. Yezli S, Shibl AM, Memish ZA. The molecular basis of $\beta$-lactamase production in Gram-negative bacteria from Saudi Arabia. J Med Microbiol. 2015;64:127-136.

2. Aly $\mathrm{M}$, Balkhy $\mathrm{HH}$. The prevalence of antimicrobial resistance in clinical isolates from Gulf Corporation Council countries. Antimicrob Resist Infect Control. 2012;1:26.

3. Aquino-Andrade A, Mérida-Vieyra J, Arias-de la Garza E, Arzate-Barbosa P, de Colsa-Ranero A. Carbapenemase-producing Enterobacteriaceae in Mexico: report of seven non-clonal cases in a pediatric hospital. BMC Microbiol. 2018;18:38.
4. D Leuthner K, Kullar R, Jayakumar B, Hewlett DA, Nguyen T, Puzniak L. Real-world evaluation of ceftolozane/tazobactam (C/T) use and clinical outcomes at an academic medical center in Las Vegas. Open Forum Infect Dis. 2017:4:2.

5. Liscio JL, Mahoney MV, Hirsch EB. Ceftolozane/tazobactam and ceftazidime/avibactam: two novel $\beta$-lactam/ $\beta$-lactamase inhibitor combination agents for the treatment of resistant Gram-negative bacterial infections. Int J Antimicrob Agents. 2015;46:266-271.

6. Merck [website]. USA: Highlights of prescribing information. Zerbaxa® (ceftolozane and tazobactam) for injection, for intravenous use; 2014

7. Carrazco I. Susceptibilidad a ceftolozane/tazobactam en cepas de pseudomonas aeruginosa resistentes a carbapenémicos en CMN La Raza. Enferm Infecc Microbiol Clin. 2018;38:280.

8. Hernández AM, Avilés RM, Castellanos CM. Susceptibilidad in vitro de Pseudomonas aeruginosa. Multidrogorresistente a ceftolozano/tazobactam en muestras clínicas de pacientes pediátricos. Enferm Infecc Microbiol Clin. 2018;38:92.

9. American Society for Microbiology. Manual of Clinical Microbiology. Eleventh edition. USA: American Society for Microbiology Press; 2015.

10. Clinical and Laboratory Standards Institute (CLSI). M100: performance standards for antimicrobial susceptibility testing. Twenty-eighth edition. USA: Clinical and Laboratory Standards Institute; 2018.

11. Alatoom A, Elsayed H, Lawlor K, AbdelWareth L, El-Lababidi R, Cardona $L$, et al. Comparison of antimicrobial activity between ceftolozane-tazobactam and ceftazidime-avibactam against multidrug-resistant isolates of Escherichia coli, Klebsiella pneumoniae, and Pseudomonas aeruginosa. Int J Infect Dis. 2017;62:39-43.

12. Garza-González E, Morfín-Otero R, Mendoza-Olazarán S, Bocanegra-lbarias $\mathrm{P}$, Flores-Treviño S, Rodríguez-Noriega E, et al. A snapshot of antimicrobial resistance in Mexico. Results from 47 centers from 20 states during a six-month period. PLoS One. 2018;14: e0209865.

13. Snydman DR, McDermott LA, Jacobusb LV. Activity of ceftolozane-tazobactam against a broad spectrum of recent clinical anaerobic isolates. Antimicrob Agents Chemother. 2014;58:1218-1223. 